\title{
Evaluación ambiental del proceso de urbanización de las cuencas del piedemonte andino de Santiago de Chile ${ }^{* * *}$
}

\begin{abstract}
Watersheds are complex environmental systems, where geomorphologic, hydrologic, climatic and ecological processes take place, and which are severely impacted by urbanisation. In this paper, six Santiago Andean piedmont watersheds have been researched, according with the degree of urbanisation that they reach, which varies between Macul-San Ramón, where about 40\% of their land covers has been already urbanised, until Pirque, where agricultural and rural features are still dominants. Using geographical information systems, the impact of urbanization on several ecological indicators, such as vegetative productivity, biomass, soil moisture and surface temperature are analysed. Total Imperviousness Areas, Runoff Coefficients and Environmentally Sensitive Areas allow the estimation of the state of the watersheds ant their contribution to the environmental health of Santiago city.
\end{abstract}

Keywords: Urban watershed management, geographical information systems, Santiago de Chile.

\section{Resumen}

Las cuencas son complejos sistemas ambientales en que se desarrollan procesos geomorfológicos, hidrológicos, climáticos y ecológicos, que son impactados por la urbanización. En este trabajo se estudian seis cuencas del piedemonte andino de la ciudad de Santiago que se encuentran en diferentes fases del proceso de urbanización, variando entre Macul-San Ramón, en donde casi el 40\% de su superficie ha sido incorporada a la ciudad, y Pirque, que mantiene aún sus características agrícolas y rurales. Empleando Sistemas de Información Geográfica, se analiza el impacto de la urbanización sobre indicadores ambientales, tales como productividad vegetal, biomasa, humedad en el suelo y temperaturas superficiales de los territorios ocupados por las cuencas. Las Áreas Totales de Impermeabilización, los Coeficientes de Escorrentía y las Áreas Sensitivas Ambientales, permiten estimar el estado de las cuencas y su contribución a la salud ambiental de la ciudad de Santiago.

Palabras clave: gestión de cuencas urbanas, sistemas de información geográfica, Santiago de Chile. 


\section{Introducción}

$\mathrm{L}$ a Planificación Ecológica de los Paisajes es una de las disciplinas que puede contribuir sustancialmente a la regulación del proceso de urbanización en áreas ambientalmente sensitivas, como es el caso del piedemonte andino de Santiago de Chile. Se trata de una disciplina que combina los aportes de la ecología con el análisis espacial aportado esencialmente por la geografía, para proporcionar argumentos, evaluar y predecir los problemas ambientales que afectan a las ciudades latinoamericanas como Santiago de Chile, así como para contribuir a la sustentabilidad de su crecimiento.

La ciudad de Santiago concentra el 43\% de la población total del país (seis millones de habitantes), cerca del $50 \%$ de la generación del Producto Interno Bruto y sobre el 65\% del producto industrial, en una cuenca ambiental semi-cerrada, formada por los ríos Maipo y Mapocho, que descienden desde la Cordillera de los Andes, cadena montañosa de gran altura que la limita por el Oriente. La interacción entre la cordillera y la llanura aluvial en que se localiza la mayor parte de la ciudad, se realiza a través de un conjunto de cauces fluviales y conos sedimentarios que originan un piedemonte que se extiende entre los 800 y 1.500 metros de altura. A través de dichos cauces y laderas circula el agua superficial y subterránea que se genera en las lluvias, nieves y glaciares que ocurren en la parte alta de la cordillera andina y que aseguran la sobrevivencia de una ciudad inmersa en un ambiente árido, donde los días promedios de lluvias alcanzan a sólo veinte en el año. El agua almacenada por procesos de recarga sobre las montañas, campos de nieve y glaciares es fundamental para el abastecimiento de la ciudad durante el largo período seco anual, y especialmente cuando tienen lugar períodos de sequía. A lo largo

* Departamento de Geografía de la Universidad de Chile/Centro EULA de Ciencias Ambientales de la Universidad de Concepción. E-mail: hromero@uchile.cl.

** Departamento de Geografía de la Universidad de Chile. E-mail: alexvasq@uchile.cl.

*** Los autores agradecen los aportes financieros brindados por los Proyectos Fondecyt No 1050423 y por el Gobierno Regional de la Región Metropolitana de Santiago. Recibido el 16 de enero de 2005, aprobado el 18 de agosto de 2005 . de estos cauces descienden también los sedimentos rocosos que cubren las laderas y que pueden originar movimientos de remoción de masa, inundaciones y aluviones, que amenazan a la ciudad cada vez que las lluvias ocurren intensamente. La impermeabilización de las cubiertas de suelos que acompaña al proceso de urbanización del piedemonte afecta directamente a la cantidad y calidad de las aguas y sedimentos que se desplazan desde las montañas, transformándose en una importante fuente de riesgos naturales, lo que exigiría la protección permanente de los bordes de los cauces y la exclusión de la urbanización de los lechos fluviales.

Antes bien, debido a la vulnerabilidad que presenta la ciudad al asentarse en medio de una cuenca ambiental dinámica, sería necesario que se evitara la urbanización de los sectores de piedemonte y que se destinara justamente a la protección de la vegetación y de los suelos que aseguran la infiltración de las aguas de las lluvias, aumentan la recarga y disponibilidad de las aguas para enfrentar los períodos de sequía y evitan o reducen la ocurrencia de inundaciones y aluviones, que han causado numerosas pérdidas de vida, destrucción de la infraestructura y las viviendas e interrupciones en la circulación y la vida normal de la metrópolis.

Por último, el piedemonte andino es fuente de aire limpio y de biodiversidad. En efecto, el piedemonte se localiza a una altura generalmente superior a los límites de las capas de inversión térmica que atrapan la contaminación atmosférica, lo que significa que las concentraciones de material particulado y de gases contaminantes son menores que en otras áreas de la ciudad, aunque la contaminación fotoquímica tiende a ser mayor por la más elevada insolación que reciben. El aire contaminado proveniente de las zonas industriales y mayormente urbanizadas del fondo de la cuenca, es transportado regularmente hacia la cordillera por los vientos y brisas ascendentes durante las tardes y desciende hacia el centro de la ciudad durante las noches y madrugadas. La falta de ventilación es una de las principales limitaciones ambientales de la ciudad de Santiago, y la razón por la cual la atmósfera se encuentra saturada por contaminantes la mayor parte del año. El piedemonte, en cambio, se encuentra usualmente sobre la nube de contaminantes y es objeto de una mayor ventilación y capacidad depuradora de 
la atmósfera. En términos de biodiversidad, en la montaña se encuentran las áreas de origen y refugio de las especies vegetales y animales nativas que circulan a través de los corredores generados por los cau- ces fluviales, donde localizan sus hábitats y cumplen sus ciclos vitales. La mayor calidad ambiental de estas áreas se manifiesta también en la existencias de numerosos remanentes de bosques y matorrales

Figura 1. Cuatro cuencas seleccionadas.

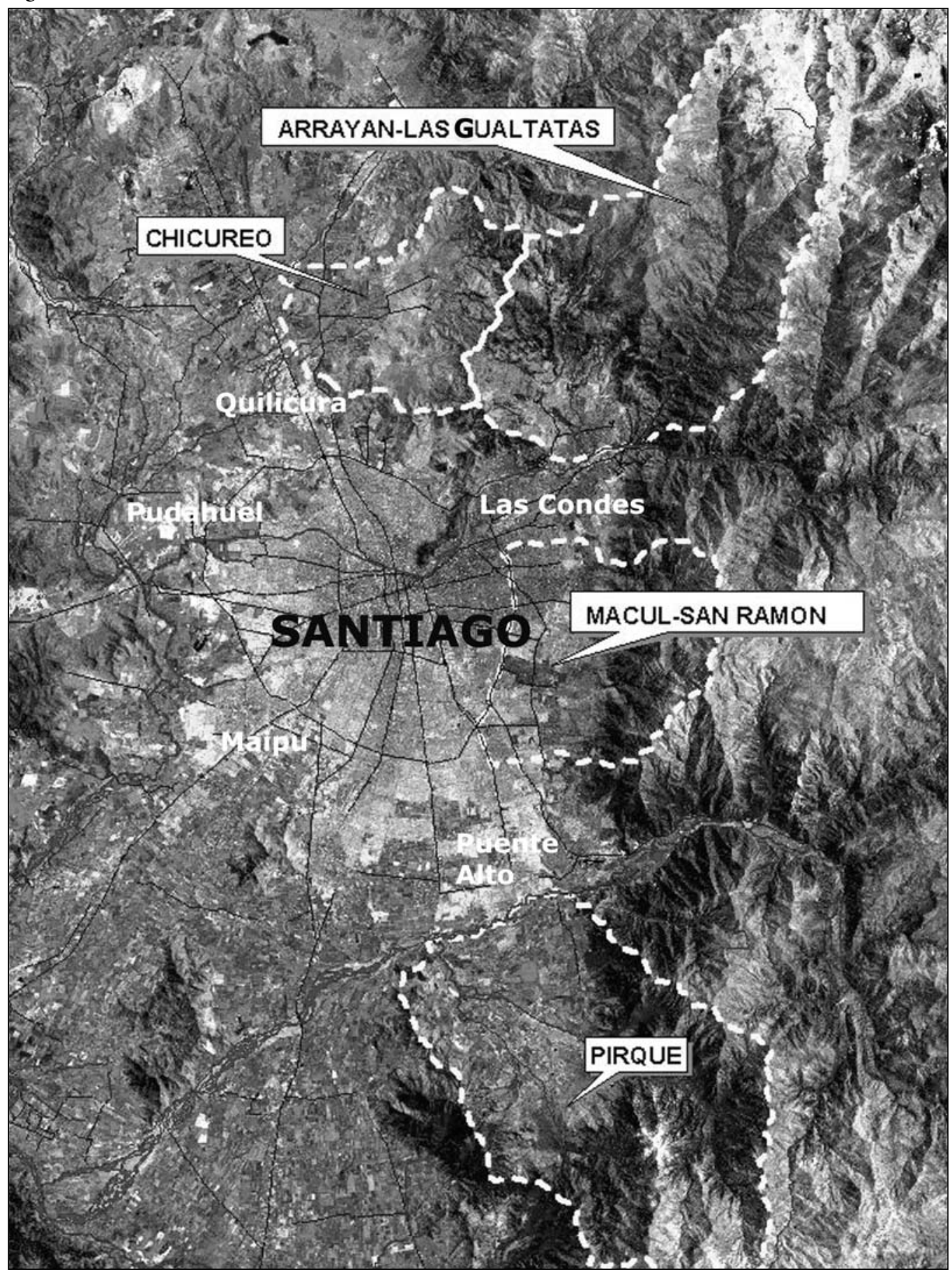


nativos, y con ello de hermosas vistas panorámicas, todo lo cual lo hace ser un área muy codiciada para la urbanización. Hasta ahora, los planes reguladores han intentado conservar estas áreas para que cumplan sus funciones y servicios ambientales, pero es evidente que las tendencias y razones para su urbanización progresan rápidamente, como lo manifiestan los nuevos condominios y áreas residenciales ubicados en los sectores más altos de las comunas de Huechuraba, Las Condes, La Reina, Peñalolén, La Florida y Puente Alto, todas ellas de vertiginoso crecimiento urbano durante las últimas décadas.

Numerosos argumentos impiden mantener las regulaciones y explican su urbanización parcial. La supuesta conservación ecológica de sus paisajes no ha ocurrido en realidad debido a la falta de instituciones y planes de gestión, así como a su dedicación temprana a propósitos silvoagropecuarios. El sobrepastoreo y la devastación de las cubiertas vegetales para elaborar leña y carbón, junto con los incendios forestales, han reducido sus funciones y servicios ambientales.

La existencia de límites a la expansión urbana mediante el empleo de curvas de nivel, si bien da cuenta de cambios importantes en la morfología del piedemonte y su vulnerabilidad sobre los 800 y 900 metros de altura, no considera la existencia de áreas con alta aptitud urbana sobre dicho límite, así como tampoco la existencia a menor altura de paisajes naturales, particularmente a lo largo de los bordes de ríos y quebradas. Adicionalmente, los nuevos instrumentos de gestión territorial del proceso de urbanización han abierto la posibilidad de extender la ciudad hacia grandes paños ubicados fuera de los límites urbanos, en la medida que cumplan un conjunto de requisitos en términos de tamaño, estructura y diseños urbanos. Se trata de las Zonas de Urbanización Condicionada (ZODUC).

Consecuentemente, es importante disponer de conocimientos que permitan evitar la generación o incremento de los riesgos naturales y la pérdida de los valiosos servicios y funciones ambientales que, aun dentro de las limitaciones mencionadas, continúa prestando el piedemonte andino de la ciudad de Santiago. Para conocer la situación actual, se seleccionaron cuatro cuencas (figural) que se encuentran en diferentes etapas del proceso de urbaniza- ción: la cuenca de Macul-San Ramón permite apreciar el estado más avanzado de ocupación urbana; la cuenca de Arrayán-Las Gualtatas, por su parte, se encuentra en una fase intermedia de avance de la urbanización, que afecta diferencialmente a sus pisos ecológicos; la cuenca de Chicureo, ubicada más al norte de la ciudad, es un ejemplo de lo que ha acontecido recientemente bajo el esquema de desarrollo urbano impulsado por las ZODUC; por último, se ha considerado la cuenca de Pirque como ilustración de un área que, no obstante las enormes presiones de urbanización, ha mantenido sus características rurales y naturales.

Este trabajo se desarrolla en cuatro etapas. La primera presenta la distribución y dinámica espaciotemporal de atributos ambientales que permiten evaluar el estado y evolución del medio ambiente natural de las cuatro cuencas fluviales seleccionadas: biomasa, humedad en el suelo, productividad vegetal y temperaturas superficiales, comparados entre 1989 y 2003 , período que comprende buena parte de la acentuación de la ocupación urbana. La integración espacial de estos atributos permitió elaborar una clasificación de la calidad del estado ambiental. Se asume que una cuenca urbanizada de alta calidad ambiental es aquella que mantiene significativas concentraciones de biomasa (abundancia de vegetación) y productividad vegetal (eficacia fotosintética para formar cubiertas vegetales), además de acumular humedad en el suelo (necesaria para la sobrevivencia de la vegetación). Desde el punto de vista de las temperaturas superficiales, se trata de áreas que alcanzan valores medios y fríos, y que por ello, exhiben una heterogeneidad térmica que aumenta el confort para la habitabilidad y asegura la generación de brisas locales y ventilación. Por el contrario, la ausencia de los componentes mencionados -es decir, la desertificación urbana caracterizada por ausencia de áreas verdes y sequedad del suelo, junto a la presencia de altas temperaturas superficiales que forman islas de calor-, corresponden a un deterioro o degradación de la calidad ambiental.

En una segunda etapa se analizan dos indicadores ambientales relevantes para comprender los efectos de la urbanización de cuencas sobre los regímenes hídricos, y consecuentemente, sobre el escurrimiento superficial de las aguas y la generación de inundaciones. Se trata de las Áreas Totales de 
Impermeabilización (ATI) y los Coeficientes de Escorrentía (CE). Cada uno de los tipos de usos del suelo/coberturas superficiales posee una tasa de impermeabilización específica, de tal forma que la impermeabilización total de la cuenca resulta de la adición ponderada de las superficies cubiertas por residencias de diferentes densidades, calles, patios, estacionamientos y cubiertas pavimentadas, áreas verdes, remanentes de vegetación natural y cultivada y suelos desnudos (May, 1998; Stanuikynas y Van Abs, 2000; Barnes et al., 2001). Las ATI aumentan dramáticamente con la urbanización de las cuencas, y por lo tanto, se relacionan directamente con los CE, los que se han calculado considerando en conjunto la inclinación de las pendientes y los usos del suelo/coberturas superficiales de las tierras.

Los mayores impactos ambientales provocados por la impermeabilización, y que afectan el equilibrio natural y la salud de las cuencas urbanizadas, son los siguientes:

\section{- Alteración del ciclo hidrológico y pérdida de calidad del agua. El reemplazo significativo de la vegetación por superficies impermeables re- duce los coeficientes de intercepción de las llu- vias por parte de los follajes (el porcentaje de agua caída que es retenido por la copa de los árboles y que escurre lentamente a través de tallos y troncos hasta alcanzar el suelo, e infil-}

trarse con mayor facilidad que si cae directamente desde las nubes sellando los suelos y favoreciendo el escurrimiento), así como el promedio anual de evapotranspiración (suma de la evaporación del agua contenida en los suelos y cuerpos hídricos y de la evaporación a través de las hojas de las plantas), y provoca alteraciones en los tiempos, tasas y volúmenes de recarga y descarga de los acuíferos subterráneos. El aumento del escurrimiento superficial ocurre como consecuencia de la disminución de la infiltración superficial y subsuperficial de los flujos de agua y facilita las inundaciones y el desplazamiento de aguas contaminadas de fuentes puntuales (efluentes de aguas servidas) y no puntuales (jardines, cultivos agrícolas, calles) hacia lagos, arroyos y estuarios.

Impactos en los balances de energía y en los microclimas. La transformación de las superficies permeables a impermeables altera localmente los balances de energía debido a que aumenta la reflexión de la radiación solar en desmedro de la absorción lenta, cambia la capacidad de calor específico y la conductividad termal de los materiales que componen la superficie de la ciudad y con ello, las tasas de calor sensible que es transferida a la atmósfera $y$ de calor latente que es empleado en la evaporación y que regresa a la atmósfera una vez

Figura 2. Relación entre la impermeabilidad de las cuencas y la calidad del cauce fluvial, y con el estado del ambiente en cuencas urbanas, según Zandbergen et al. (2000).

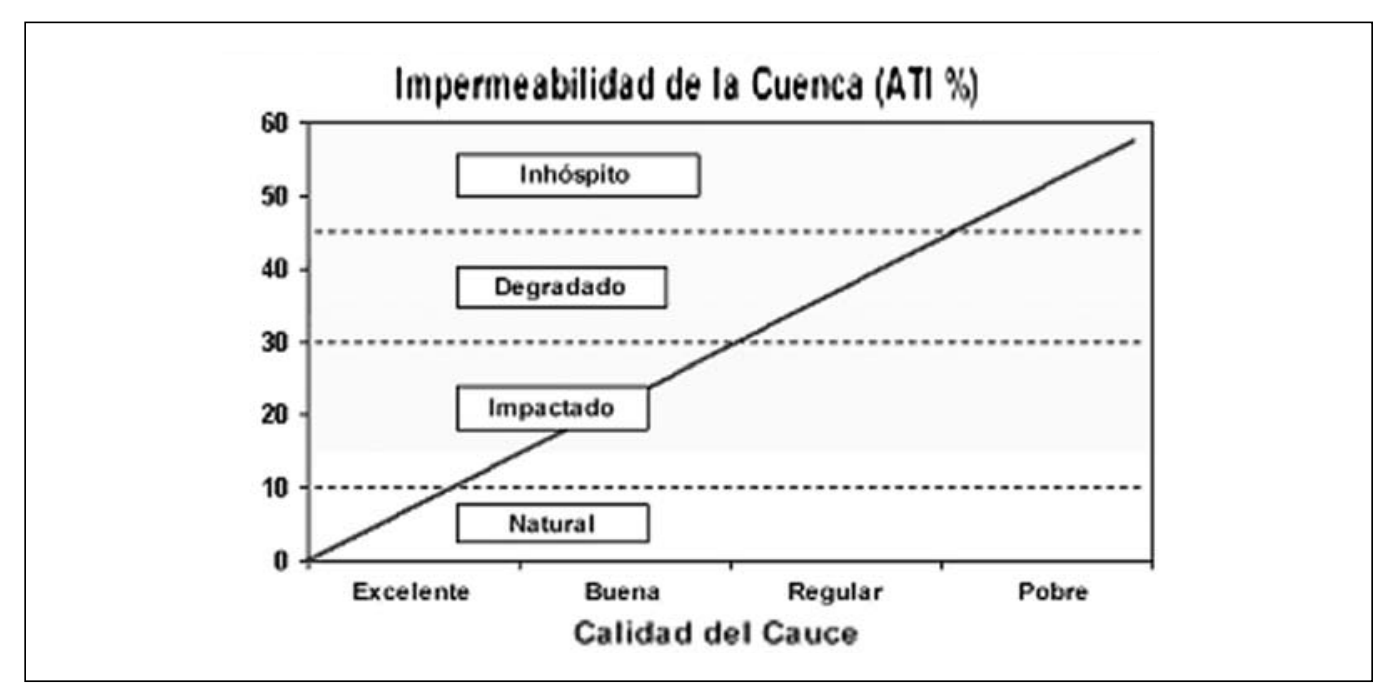


que se produce el proceso de condensación de la humedad atmosférica (Oliver, 1973). Cabe esperar en consecuencia el desarrollo de áreas de mayor temperatura y la generación de islas de calor, que son características en las áreas de mayor densidad residencial, industrial o comercial de las ciudades.

- Degradación, pérdida y fragmentación de hábitats acuáticos y terrestres, que se degradan y destruyen al impermeabilizar sus superficies. Algunas especies muestran signos de estrés y disminución de su población con un $10 \%$ de superficies impermeabilizadas.

- Degradación de los arroyos. La impermeabilización de los cauces naturales y su reemplazo por alcantarillados, cursos de agua canalizados y obstruidos, además de la simplificación de la red de drenaje, aumentan la velocidad de los flujos de agua, causando un aumento de la potencia erosiva y mayor producción de sedimentos.

- $\quad$ Efectos sobre los hábitats terrestres. La impermeabilización causa la destrucción y fragmentación de los hábitats terrestres, y un estrés inmediato en las plantas y vida silvestre, provocando la pérdida de biodiversidad a través de impactos acumulativos que se manifiestan en forma lenta.

\section{- Cambios en la estética de los arroyos y paisa- jes.}

Los estudios realizados sobre la impermeabilización como efecto de la urbanización concluyen que se trata de un importante indicador sobre la calidad y la salud de las cuencas mediante, y que ambos procesos se relacionan linealmente, como se puede apreciar en la Figura 2 (May, 2001; Zandbergen et al., 2000).

La tercera sección de este trabajo analiza las cuencas urbanizadas desde la perspectiva de la ecología de los paisajes, mediante la consideración de atributos espaciales relacionados con la presencia, localización y distribución de parches y corredores vegetales. Para la ecología de paisajes, las ciudades corresponden a un complejo mosaico de usos y coberturas del suelo, que puede ser representado por unidades espaciales aisladas y diferentes llamados parches, que conforman corredores cuando dos o más parches articulan flujos en el sistema (Vásquez, 2002). La comparación entre los años 1989 y 2003 permite conocer los impactos de la urbanización sobre la vegetación, determinando las variaciones en el número, tamaño promedio, área, perímetro total y perímetro promedio de los parches vegetales. La vegetación es el componente ambiental que oferta más funciones y servicios ambientales a la ciudad: mitigación de las islas de calor y generación de islas frías, filtro y reciclaje de los contaminantes atmosféricos, incremento de la infiltración de las aguas de lluvia, control del escurrimiento y las inundaciones, áreas de refugio y hábitats para la vegetación, depuración de las aguas y sedimentos que convergen a los cauces, sitios de recreación y turismo, etc. (Romero et al., 2003).

En la última parte se presentan las Áreas Sensitivas Ambientales (ASA), con el propósito de obtener criterios específicos que contribuyan a incluir su protección y manejo como condicionantes para la urbanización de las cuencas. Las ASA corresponden a áreas que concentran las cubiertas vegetales de mayor superficie, complejidad, diversidad y conectividad, y por ello, que generan la mayor cantidad y calidad de servicios ambientales. Las Áreas Críticas Ambientales (ACA), por su parte, corresponden a aquellas en que la pérdida o deterioro de sus estructuras y funciones es responsable del deterioro de su calidad ambiental y de los servicios ambientales que deberían ofrecer a la ciudad. Por ello, no sólo es necesario preservarlas, sino que además se deben iniciar planes destinados a su restauración o rehabilitación.

\section{Metodología}

\subsection{Componentes y calidad ambiental de las cuencas}

Los componentes ambientales de las cuencas urbanizadas fueron identificados a partir del análisis digital de imágenes satelitales LANDSAT TM (satélite espacial que capta cada dieciocho días imágenes en siete bandas del espectro electromagnético, dando cuenta de las reflexiones y emisiones de los diferentes cuerpos que ocupan la superficie terrestre, a través de cuadrículas o pixeles que cubren una 
superficie de 18 x 18 metros. La combinación de imágenes captadas en las diferentes bandas se asocia con rasgos del medio ambiente físico tales como brillo, verdor y marchitez de la vegetación (ERDAS, 1997; Eastman, 1999).

Para la estimación de la productividad vegetal se utilizó el Índice de Vegetación de Diferencia Normalizada (Normalized Difference Vegetation Index, NDVI), derivado de la reflectividad medida en las regiones roja e infrarroja cercana del espectro electromagnético. Las temperaturas superficiales, por su parte, fueron obtenidas a partir de la consideración de las emisiones captadas en la banda infrarroja cercana.

\subsection{Análisis de la impermeabilidad}

El Área Total Impermeable (ATI) de una cuenca corresponde a la suma ponderada de las tasas específicas de impermeabilidad de las superficies ocupadas por diferentes usos/coberturas de la tierra, siendo considerablemente mayor en zonas residenciales densas, industriales y comerciales, que en áreas de viviendas unifamiliares, agrícolas o con dominancia de coberturas vegetales.

Existen numerosas fuentes para estimar el porcentaje de impermeabilidad, ya sea a través de información empírica (mediciones en terreno), estimaciones a través de fotografías aéreas o bien a través de la consideración de áreas pavimentadas en imágenes satelitales (Zandbergen et al., 2000). En este trabajo, la metodología utilizada es similar a la empleada por el Proyecto de Manejo de la Cuenca de Raritan, Nueva Jersey, Estados Unidos (Stanuikynas y Van Abs, 2000), que propone calcular el porcentaje de impermeabilidad (PI) para cada polígono identificado en la clasificación combinada de Uso/Cobertura del Suelo (UCS). El PI se clasifica en intervalos de $10 \%$, y cualquier polígono que contenga pavimentos dentro de su superficie obtendrá a lo menos un $10 \%$ de PI.

\subsection{Coeficiente de Escorrentía}

Se denomina escorrentía a la precipitación efectiva o excedente de agua que fluye por diferentes caminos hacia la red de drenaje, tanto a nivel superficial como subsuperficial y subterráneo. El desplazamiento del agua depende principalmente de la pendiente, cobertura vegetacional y estructura del suelo (Martínez y Navarro, 1995). El uso permanente del piedemonte andino a través de la urbanización y la obtención de materias primas (madera, leña, carbón) y el uso ganadero, han contribuido a la degradación de la cubierta vegetal, alterando la escorrentía y disminuyendo la oportunidad de infiltración de las aguas.

\subsection{Clasificación de Uso/Cobertura del Suelo}

El uso del suelo se entiende como el destino asignado por el hombre a cada unidad de territorio, e incluye áreas comerciales, habitacionales e industriales, así como zonas agrícolas y terrenos forestales, entre otros. La cobertura del suelo, por su parte, se refiere específicamente a las unidades vegetacionales que cubren la superficie terrestre, diferenciándolas por estructura (praderas, matorrales, matorrales arborescentes, bosques, plantaciones) y densidad (abierto, semidenso, denso).

La clasificación de los usos y coberturas del suelo permitió estimar la impermeabilización y escorrentía superficial en cada unidad de paisaje. Los tipos de uso y coberturas del suelo considerados correspondieron a:

Zonas urbanas. Incluyen la periferia de la ciudad, caracterizada por viviendas unifamiliares y "parcelas de agrado" (viviendas construidas en terrenos sobre 0,5 hectáreas que mantienen su clasificación de tierras rurales), usos industriales, comerciales y áreas destinadas a transporte (carreteras, líneas férreas), y áreas verdes urbanas.

Zonas agrícolas de uso intensivo y extensivo.

Praderas y matorrales. Coberturas vegetales mayoritariamente herbáceas de origen natural (praderas andinas) o antrópicas (praderas para ganadería), matorrales y matorrales arborescentes con densidades abierta, semidensa y densa.

Bosques y plantaciones forestales, distinguiendo entre nativos y exóticos.

Otros Usos/Coberturas de suelo. Agrupa categorías dispersas como cuerpos de agua naturales y artificiales, zonas rocosas, suelo desnudo, nieves y glaciares y zonas no identificadas. 
Para la clasificación de Usos y Coberturas de Suelo de las cuencas se utilizaron fotografías aéreas a color, escala 1:115.000, en formato digital, provenientes del vuelo CONAMA 2001, obtenidas a partir del Sistema Nacional de Información Ambiental. La asociación espacial entre UCS/ ATI consideró las relaciones entre las tasas de cambio en los flujos hidrológicos causados por la impermeabilización (Arnold y Gibbons, 1996) (figura 3).

\subsection{Parches y corredores vegetales}

Se definieron como parches y corredores vegetales las áreas que presentan una alta productividad vegetal (NDVI>dos desviaciones estándar respecto a la media de la imagen Landsat TM). Cuando la distancia entre dos parches era menor a un pixel, se estableció que se trataba de parches vegetales. Considerando parches y corredores vegetales se construyeron los siguientes mapas temáticos:

- Parches vegetales localizados dentro de los límites de cada una de las cuencas en 1989 y 2003.

- Cambios (pérdida y fragmentación) de parches vegetales entre 1989 y 2003.
- Parches vegetales según tipo de vegetación, productividad vegetal y estructura horizontal y vertical.

Si bien existen numerosos atributos espaciales que permiten evaluar las funciones y servicios ambientales proporcionados por parches y corredores vegetales localizados al interior de la ciudad (número, superficie, proximidad, área interior, convolución, etc.), es la reducción del tamaño de los parches y corredores -aunque aumente el número de los mismos- lo que implica una fragmentación espacial que repercute por lo general en forma negativa sobre los servicios ambientales y la biodiversidad (Romero $e t$ al., 2001 y 2003).

Mientras mayor sea el número y superficie de los parches vegetales, mayor será la cantidad, diversidad y calidad de las especies biológicas y de los servicios ambientales que presten al funcionamiento de la matriz urbana. El tamaño del parche es el atributo espacial de mayor importancia ecológica (Sukkop, 1991; Dramstad et al., 1996; Forman, 1997), por cuanto los grandes parches protegen la calidad de los acuíferos y del agua, conectan las especies y flujos (de sedimentos, agua, aire e informaciones), se constituyen en

Figura 3. Cambios en los flujos hidrológicos por efectos de la impermeabilización, según Arnold y Gibbons (1996).

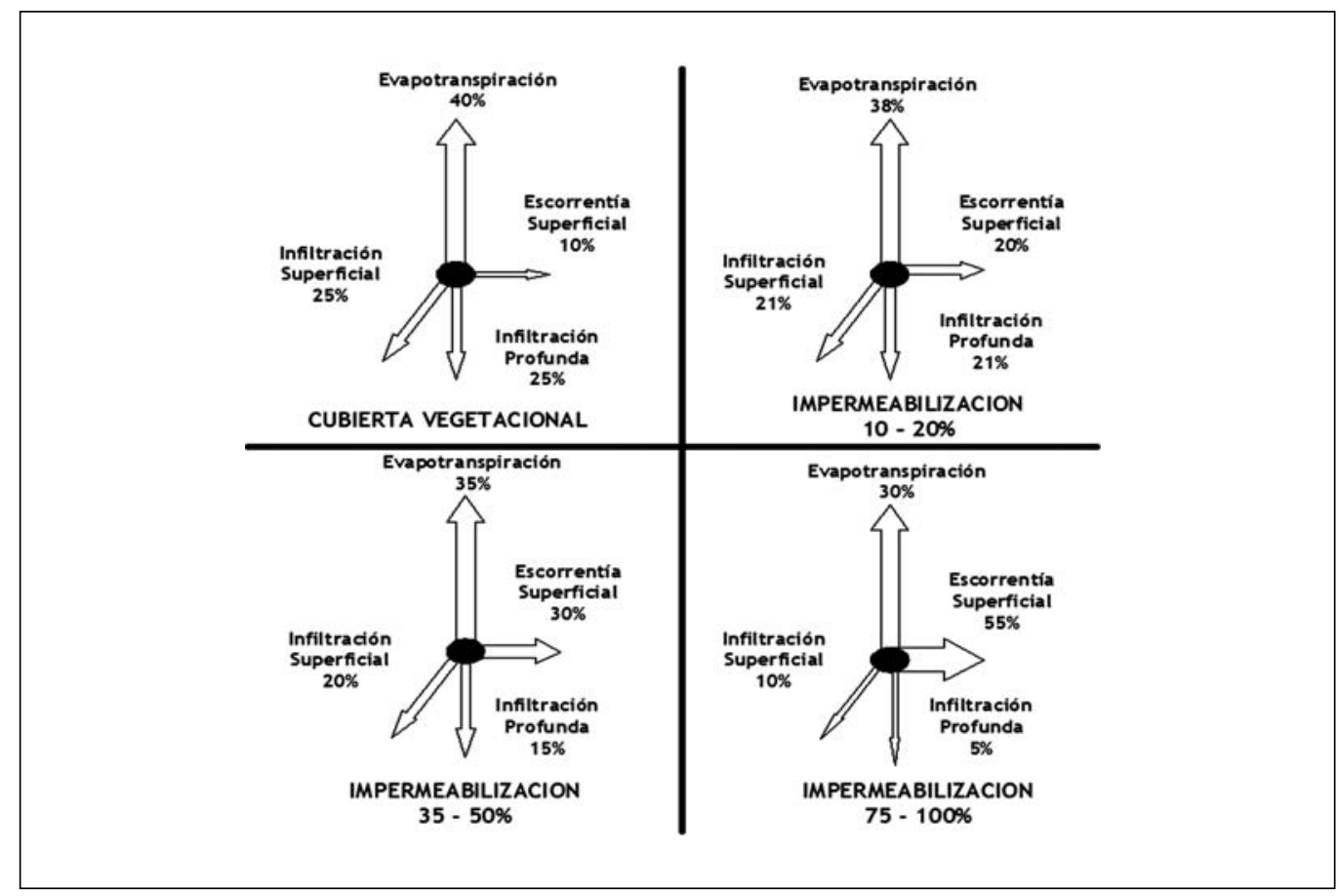


hábitats que sustentan las poblaciones interiores y actúan como fuentes de especies y servicios ambientales. Los parches pequeños, aunque no cumplen las funciones de los más grandes, pueden ser hábitat, fuentes y escalones eficaces para la dispersión de las especies y los flujos a través de la matriz urbana.

La localización relativa de los parches respecto a la matriz urbana, su conectividad y posición topológica, determinan las funciones ambientales que cumplen, tales como actuar como corredor, escalón o fuente en términos de los flujos de materia, energía e información (movimiento de las especies biológicas, aire, agua y sedimentos). La remoción, disminución y desconexión de los parches vegetales causan la pérdida de los hábitats y con ello de las especies biológicas y de los servicios ambientales que ofrecen a la ciudad.

Los bordes corresponden a la porción exterior de los parches, que separa al conjunto de condiciones que se encuentran al interior y exterior de éstos. Mientras mayor sea la superficie cubierta por los parches vegetales, se desarrollará un área interior más amplia, donde se podrán generar y conservar mejor los servicios ambientales y las especies biológicas. $\mathrm{Al}$ fragmentarse los parches en unidades de menor superficie disminuirán las funciones propias del interior y aumentarán los efectos de borde (Bustamante y Grez, 1995), caracterizados por la mayor influencia de las características ambientales urbanas sobre las condiciones existentes al interior de los parches. La mayor o menor influencia de las condiciones exteriores e interiores depende también de la geometría de los bordes. Mientras más convolucionada (rugosidad de mayor magnitud en el perímetro) sea la forma de un parche, medida por el número de lóbulos, mayores serán también las interacciones, positivas o negativas, entre los parches y la matriz urbana que lo rodea. Debe tenerse en cuenta, por lo tanto, que sólo amplias superficies vegetadas, cubiertas por conjuntos complejos de especies, pueden contribuir significativamente a mejorar las condiciones ambientales de las ciudades, existiendo en la actualidad indicadores que permiten estimar las superficies y composiciones de especies que garantizan funciones ecológicas en función de tasas de secuestro de contaminantes atmosféricos, filtro biológico de las aguas o mitigación de ruidos.

La integración y superposición de las variables indicadas permitió definir unidades homogéneas desde el punto de vista ecológico y estimar su valor ambiental, considerando su contribución a la biodiversidad, a la diversidad de paisajes y a los servicios ambientales que prestan a la ciudad.

\subsection{Areas Sensitivas Ambientales (ASA)}

Las Áreas Sensitivas Ambientales (ASA) contienen elementos del paisaje -naturales, biológicos o culturales- que son significativos para el funcionamiento del sistema ambiental en su totalidad y que -por lo tanto- deben ser protegidos por la planificación ecológica del territorio. Las ASA incluyen áreas de humedales, zonas de buffers riparianos (franjas vegetales que se desarrollan a lo largo de las riberas de ríos y arroyos como consecuencia de la acumulación de mayor humedad en el suelo), hábitats de vida silvestre o áreas de protección de especies en peligro, planos de inundación, etc.

Las ASA pueden ser identificadas y clasificadas según, entre otros atributos, su unicidad, representatividad, riesgo, valor ambiental y funciones, dentro de los ciclos del sistema ambiental total. La Tabla 1 señala los criterios considerados en este trabajo.

Se distinguieron dos tipos de áreas sensitivas: áreas ambientalmente sensibles y áreas ambientalmente críticas. Las primeras se caracterizan por la presencia de parches vegetales de gran

Tabla 1. Criterios y rangos utilizados para determinar áreas sensitivas ambientales.

\begin{tabular}{|l|l|}
\hline \multicolumn{1}{|c|}{ Criterio } & \multicolumn{1}{c|}{ Rango } \\
\hline Tamaño de parches vegetales & Grande, regular, pequeño \\
\hline Heterogeneidad interna de los parches & Alta, media, baja \\
\hline Escorrentía superficial & Muy alta, alta, media, baja, muy baja \\
\hline Aptitud de uso biológico & Muy alta, alta, media, baja, muy baja \\
\hline Calidad ambiental & $\begin{array}{l}\text { Mayor NDVI, humedad y biomasa en el suelo } \\
\text { (sobre una desviación estándar); islas frías } \\
\text { y temperaturas templadas }\end{array}$ \\
\hline
\end{tabular}


tamaño y una alta heterogeneidad interna, en donde predomina la infiltración sobre la escorrentía. Presentan además una alta aptitud de uso biológico y calidad ambiental, por lo que ofrecen servicios ambientales significativos para la salud ambiental de la cuenca, tales como zonas de infiltración y recarga de acuíferos, hábitat de especies, purificación y aporte de humedad al aire.

Las áreas críticas, en cambio, presentan paisajes muy fragmentados y poca complejidad en sus comunidades vegetales (parches vegetales pequeños y con baja heterogeneidad interna), altos porcentajes de impermeabilización y baja aptitud de uso biológico, y finalmente, concentraciones bajas de humedad y biomasa. Son áreas que se encuentran en una situación crítica y por ello son muy vulnerables a las fluctuaciones en los balances de masa (agua, sedimentos y genes) y energía. Bajo las condiciones actuales, estas áreas prestan servicios ambientales mínimos a la salud de las cuencas, por lo que corresponde protegerlas, restaurarlas y rehabilitarlas.

\section{Resultados y discusión}

\subsection{Impacto del crecimiento urbano sobre los componentes ambientales}

Productividad vegetal y biomasa. La cuenca de Pirque, de mayor ruralidad, ha mantenido en forma estable sus áreas de máxima productividad vegetal (figura 4) y biomasa (figura 5). Macul-San Ramón, por el contrario, que es la cuenca más urbanizada, si bien también presenta estabilidad para estos indicadores en el tiempo, registra las menores concentraciones espaciales de ambos componentes ambientales. Chicureo, por su parte, ha experimentado un importante descenso los dos últimos años asociado a su reciente urbanización, mientras que Arrayán-Las Gualtatas ha descendido gradualmente, aunque manteniendo un área considerable de alta productividad vegetal, y triplicando la concentración de biomasa en su parte alta desde 1998 .

Humedad del suelo (figura 6). Todas las cuencas, excepto Chicureo, presentaron una importante desecación con motivo de la sequía que afectó a la Región Metropolitana en 1998.
Seguramente el riego asociado a actividades agrícolas y generación de jardines domiciliarios en Chicureo explicaría su comportamiento diferente. Comparativamente, la cuenca menos urbanizada (Pirque) aumentó considerablemente el área de máxima humedad, mientras que las de mayor urbanización (Macul y Arrayán) mantenían sus superficies con valores relativamente más bajos.

Temperaturas superficiales (figura 7). Chicureo ha experimentado un importante descenso en el número de las áreas de mayor concentración de temperaturas (islas de calor) en los últimos años, asociado probablemente al uso intensivo del riego en los jardines que se han creado con la urbanización o bien a las áreas agrícolas remanentes. Por el contrario, Pirque y Macul han aumentado ligeramente sus superficies cálidas, y Arrayán, después de haber aumentado fuertemente sus áreas cálidas entre 1989 y 1998, disminuyó en el siguiente periodo para estabilizarse en los últimos años. Lamentablemente, no resulta posible separar los cambios acaecidos en las temperaturas de emisión de los suelos -que se pueden deber a los aumentos en las áreas de urbanización- de los cambios causados por modificaciones en la humedad de los suelos que emiten las temperaturas, y que fueron directamente afectados por la sequía de 1998 .

\subsection{Estimación de la impermeabilidady escorrentía}

Usos y Coberturas del Suelo. Las praderas y matorrales cubren el 57,3\% de la superficie total de las cuencas del piedemonte andino de Santiago, lo que refleja la naturaleza esencialmente montañosa y árida de los paisajes, excepto la cuenca de Macul-San Ramón, donde dominan los usos del suelo urbanos densos o semidensos (39,7\% de la superficie). Las áreas aún ocupadas por la agricultura son altamente variables: en las cuencas de Pirque y Chicureo alcanzaban un 17,7\%; en MaculSan Ramón sólo un 4,7 \%, mientras que en la cuenca de Arrayán-Las Gualtatas eran inexistentes. Esta última unidad presenta, en cambio, una proporción importante de pra- 
deras naturales de uso ganadero, incluidas aún dentro de ciclos de transhumancia estacional.

Impermeabilidad. Las Áreas Totales de Impermeabilización se relacionan en forma directa con la proporción de suelos urbanizados en las cuencas que alcanzan los valores extremos, como lo demuestran los valores mínimos de las ATI de Pirque (1,6, figura 8) y los valores máximos registrados en Macul-San Ramón $(23,0)$. Sin embargo, dicha relación directa no se observa en el caso de las cuencas con niveles medios de urbanización, como lo demuestra el hecho de que el ATI de Chicureo $(5,3)$ es mayor que el de Arrayán-Las Gualtatas $(4,1)$, aunque sus áreas urbanizadas sean menores. Estas diferencias se deben a la importancia que adquieren, en términos comparativos, los otros usos del suelo que existen al interior de las cuencas además de la urbanización, que contribuyen a aumentar o disminuir la impermeabilización total de las cuencas; a las densidades de las urbanizaciones, a la influencia de los diseños urbanos específicos sobre los niveles de escorrentía $\mathrm{y}$ al hecho de que las tasas tienden a aumentar exponencialmente una vez superado cierto umbral, como lo demuestra el alto valor alcanzado por Macul-San Ramón.

Las ATI de los usos urbanos registrados en las cuencas del piedemonte andino de Santiago son, sin embargo, inferiores a los valores más bajos considerados por la literatura internacional como dañinos para la salud de las cuencas, lo que estaría indicando la existencia de condiciones aún favorables en el caso de Santiago, en la medida que se limite la urbanización, se seleccione su diseño y se emprenda una gestión integral de los usos del suelo a escala de subcuencas.

El uso urbano multifamiliar, que con su $59 \%$ de impermeabilización supera ligeramente el umbral de calidad ambiental, exigiría medidas especiales de conservación y restauración de los paisajes en que se asienta. Distinto es el caso de las vías de transporte, en cuyo caso la impermeabilización alcanza al 100\%, demostrando que no existe consideración alguna por este factor en su diseño e implantación territorial.

Respecto a las zonas agrícolas que aún subsisten en el piedemonte andino, las tasas de impermeabilización de los campos que aún mantie- nen cultivos intensivos, viñedos y frutales equivalen a los valores medios internacionales, por lo que se debería asegurar su aporte a la salud ambiental de las cuencas y evitar su sustitución por superficies urbanas. La mayor diferencia entre las condiciones del piedemonte andino de Santiago y los valores internacionales de referencia corresponde a los matorrales arbustivos, abiertos y semidensos, que con sus 12,5 y 8,5 de impermeabilización, respectivamente, superan con creces el valor 5 , considerado como máximo para conservar el aporte de este tipo de formaciones vegetales a la salud ambiental de las cuencas. Ello implica la necesidad de intervenir estos paisajes para reducir y evitar sus elevados aportes a la impermeabilización de las cuencas, requiriéndose especiales esfuerzos de reforestación y restauración de los ecosistemas y de la ecología de paisajes.

Destaca como patrón general la acumulación de zonas impermeables en la parte baja de las cuencas, como consecuencia de la urbanización. Esta zona baja es la que cumpliría mejor la función y servicio de recarga de los acuíferos para la cuenca de Santiago. Al impermeabilizar las zonas de recarga se convierten irreversiblemente en zonas de descarga, potenciando el volumen y velocidad del escurrimiento superficial y alterando la profundidad de los acuíferos. Esto aumenta a su vez el riesgo de inundaciones asociadas a la ocurrencia de lluvias torrenciales y la falta de abastecimiento en los períodos de sequía, así como la variabilidad -y eventualidad- de los flujos de agua que circulan en los cauces naturales. Esto provocaría a su vez una alteración en el balance térmico de la cuenca, promoviendo el aumento de temperaturas en la época estival.

Respecto a la relación entre impermeabilización y escorrentía, al aumentar la primera se generan procesos de acumulación de agua que generalmente se traducen en inundaciones urbanas. Los estudios de Arnold y Gibbons (1996) plantean que Tasas Totales de Impermeabilización como las observadas en las cuencas de Pirque, Chicureo y Arrayán-Las Gualtatas, equivaldrían a aportes de $10 \%$ a la escorrentía superficial, $40 \%$ a la evapotranspiración, $25 \%$ a la infiltración superficial y $25 \%$ a la infiltración profunda. En el caso de la cuenca de Macul-San Ramón, la urbanización habría significado que la escorrentía superficial aumentara a un $20 \%$; la infiltración profunda y su- 
Hugo Romero y Alexis Vásquez

Figura 4. Variación de las áreas de mayor concentración de pruductividad vegetal en las cuencas seleccionadas (1998-2003).

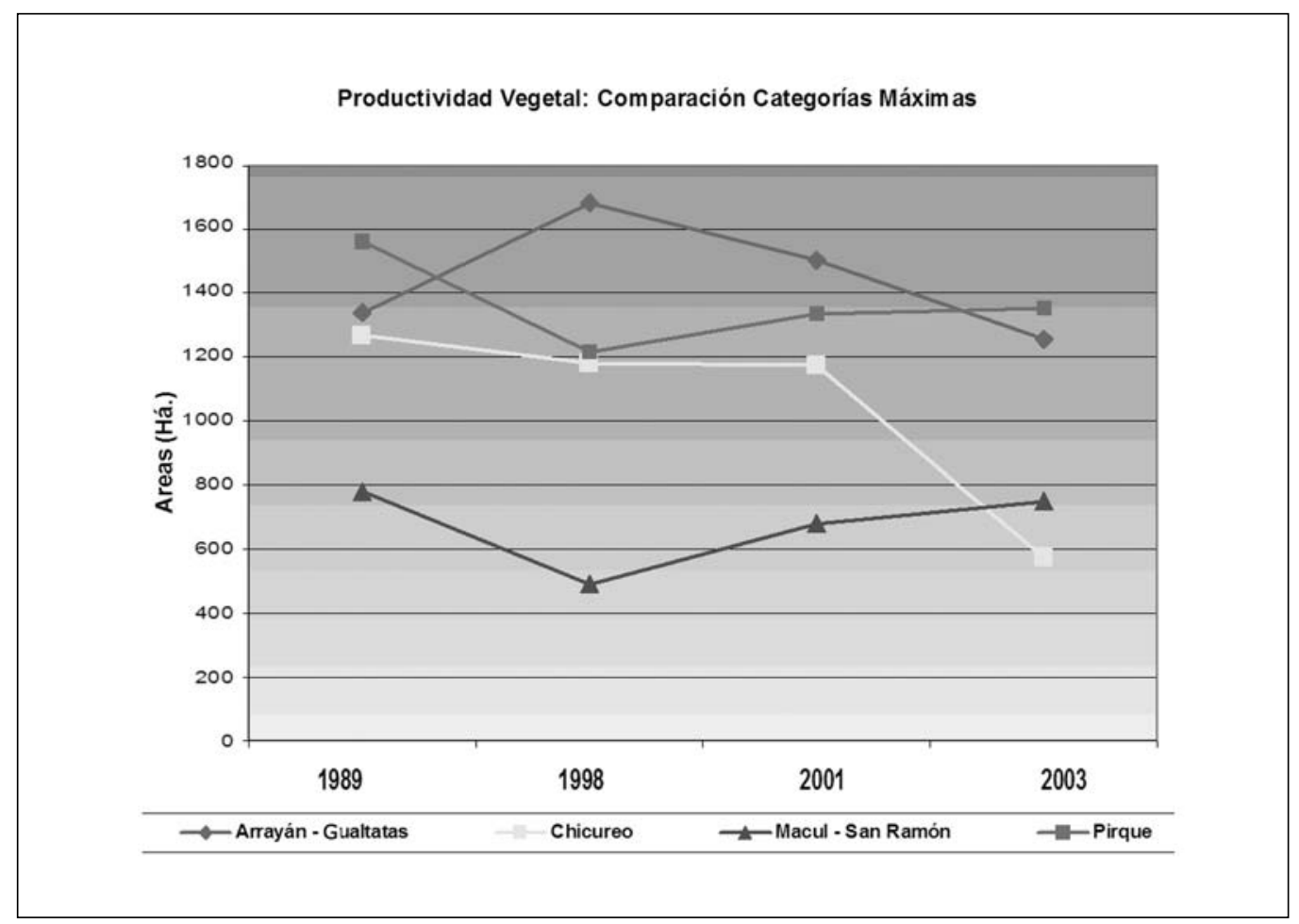

Figura 5. Variación de la concentración máxima de biomasa en el suelo en las cuencas del piedemonte andino en Santiago (1989-2003).

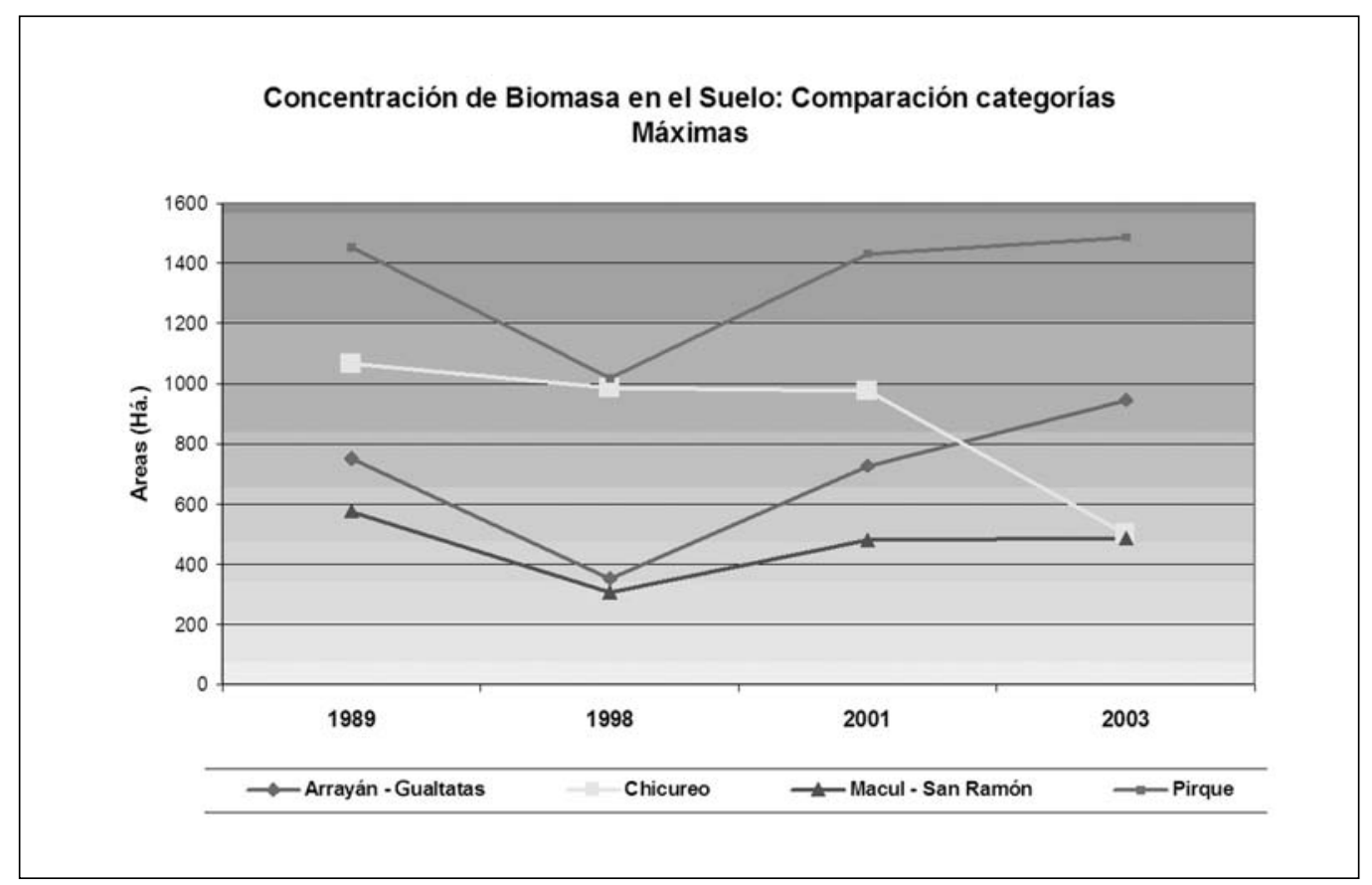


Evaluación ambiental del proceso de urbanización de las cuencas del piedemonte andino de Santiago de Chile

Figura 6. Variación del contenido máximo de humedad en el suelo en las cuencas del piedemonte andino de Santiago (1989-2003).

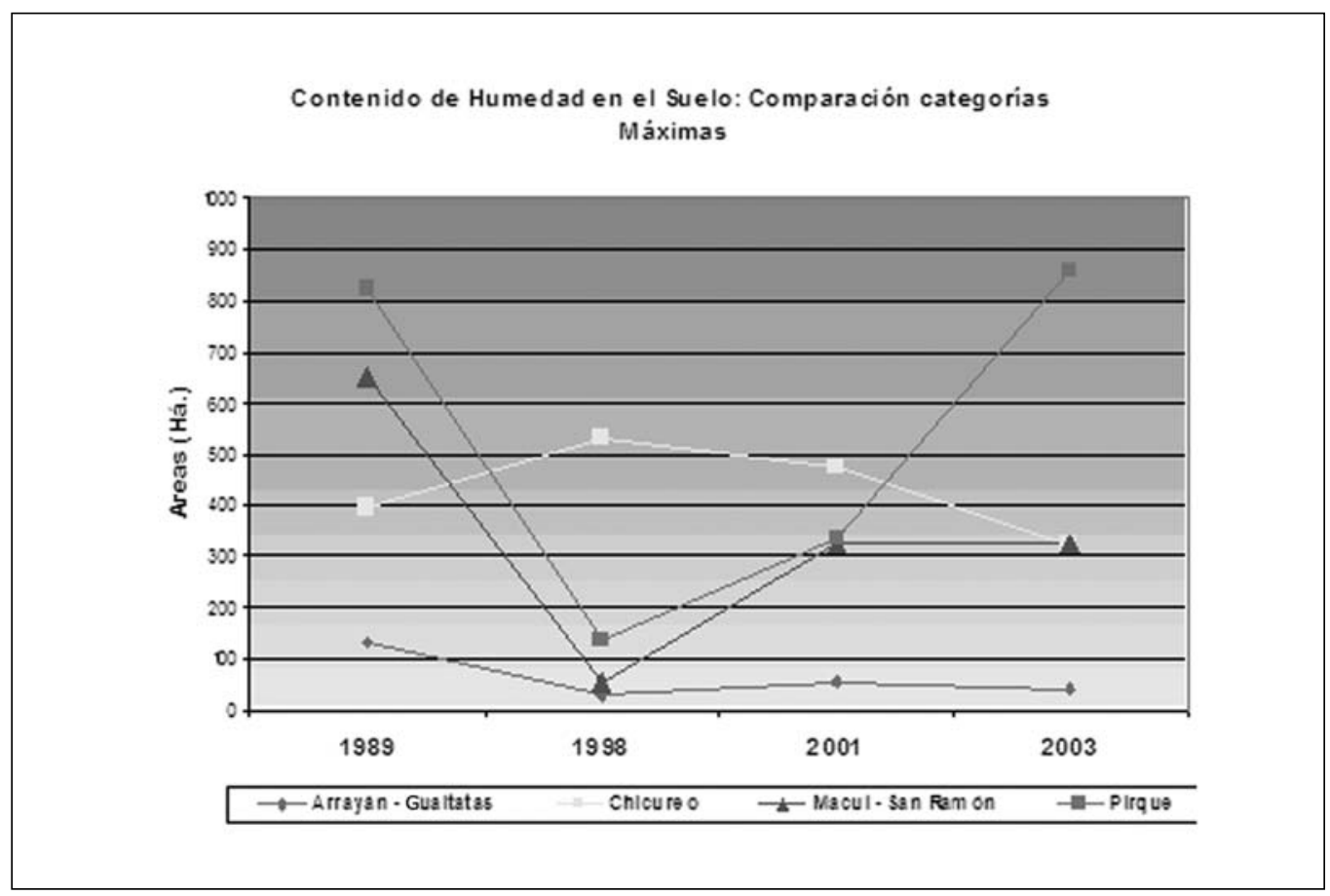

Figura 7. Variación de las temperaturas máximas de emisión superficial en las cuencas del piedemonte andino de Santiago (1989-2003).

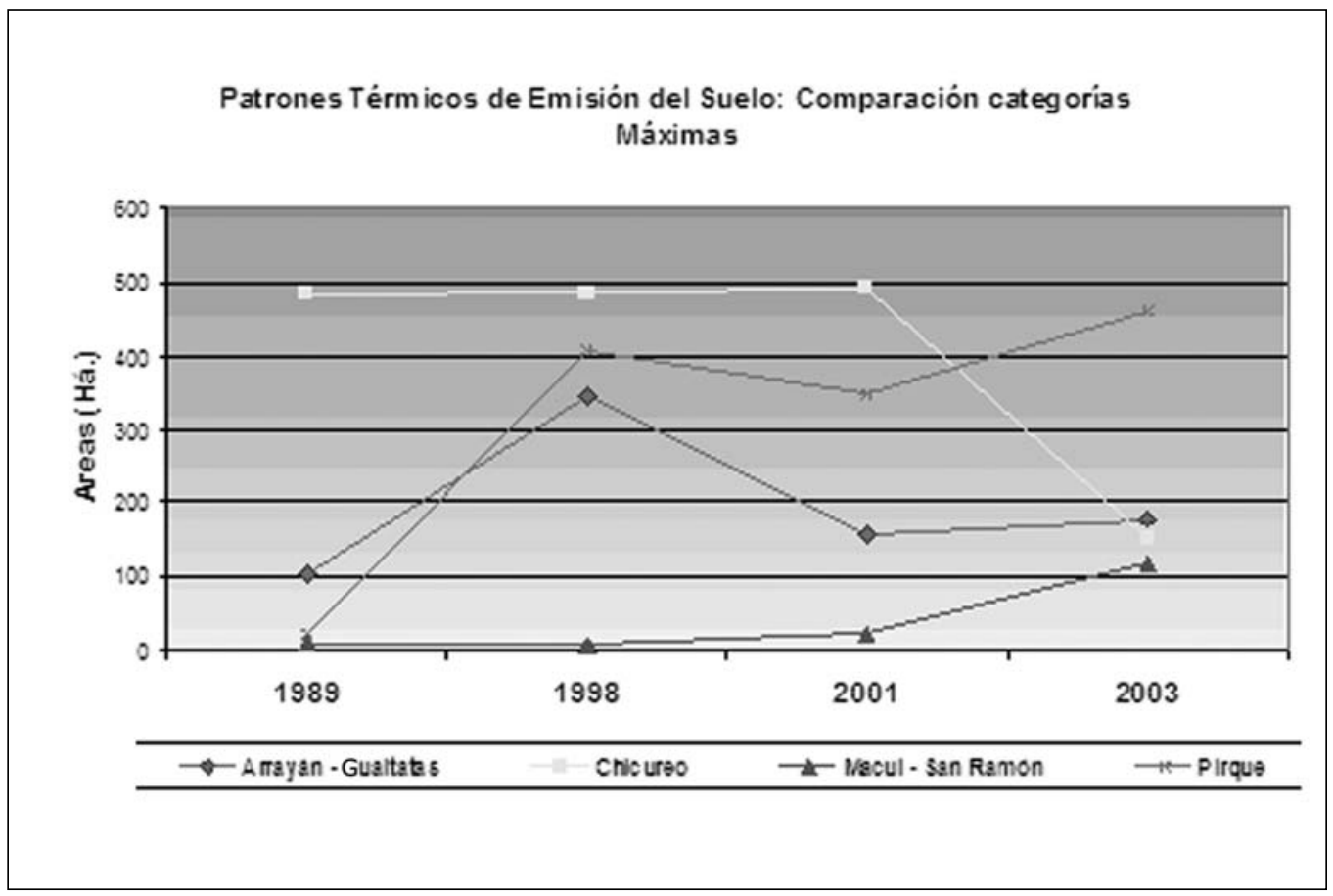


Figura 8. Relación entre la urbanización e impermeabilidad en cuatro cuencas del piedemonte de Santiago.

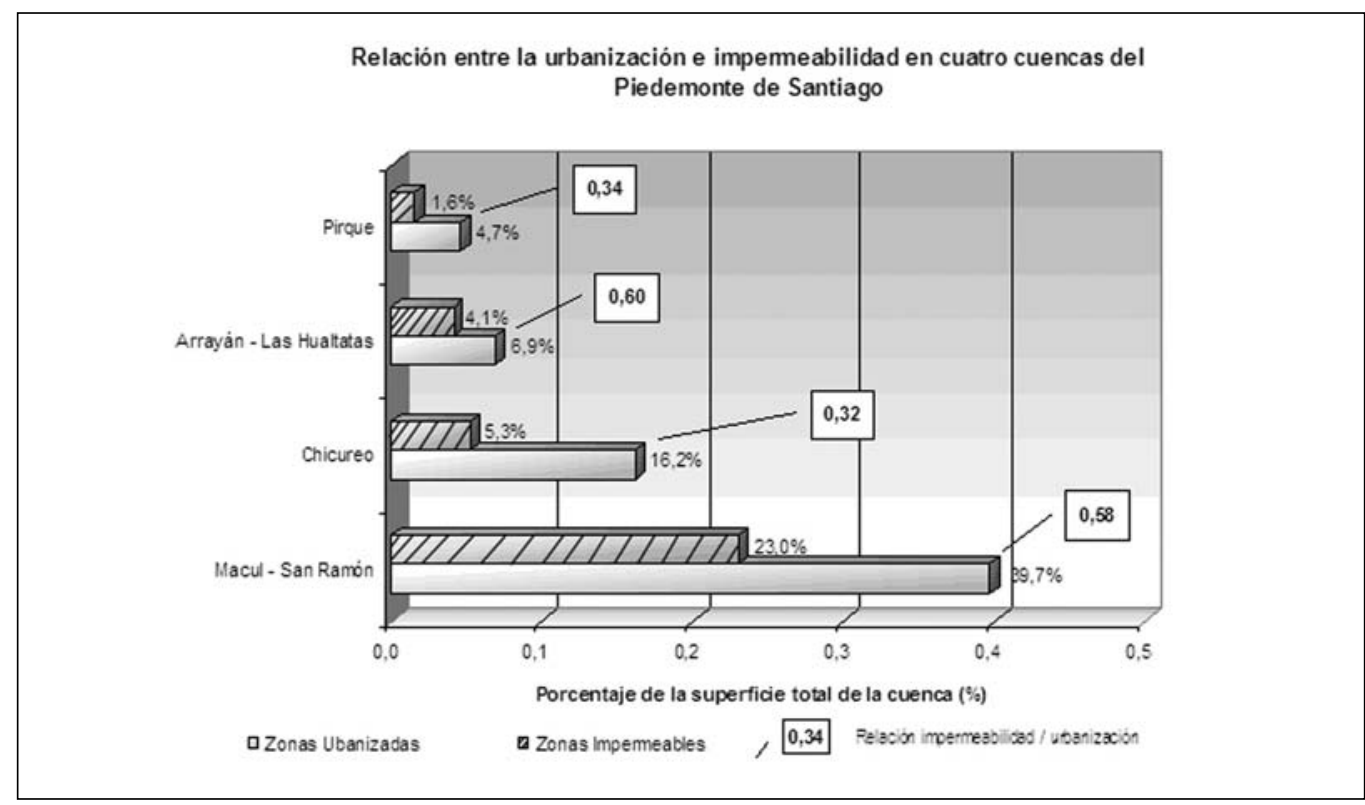

perficial disminuyera a un $21 \%$, respectivamente, y la evapotranspiración se redujera a un $38 \%$.

Respecto a los efectos de la urbanización sobre la calidad de las aguas, es relevante considerar el aporte de contaminantes desde fuentes no puntuales al cauce principal. Las primeras lluvias arrastran los contaminantes existentes en las calles hacia los ductos de aguas lluvias (que en el caso de Santiago aún no se encuentran separados de los colectores de aguas servidas), o bien directamente hacia el cauce fluvial, incorporando material proveniente de restos de neumáticos, aceites de vehículos, y químicos y tóxicos de distinta naturaleza (Van Bohemen y Janssen Van de Laak, 2003).

Por otro lado, se observan dos clases de relaciones entre las tasas de impermeabilización y las de urbanización en las cuencas de Santiago. En primer lugar, proporciones cercanas a 0,6 , que ofrecen las cuencas de Arrayán-Las Gualtatas y Macul-San Ramón; y en segundo lugar, las de Chicureo y Pirque, con proporciones cercanas a 0,3 . Esto implica, para el primer caso, que cada $5 \%$ de aumento de la superficie urbanizada el ATI se incrementa en 1,5\%; mientras que en el caso de Chicureo y Pirque un incremento del 5\% de urbanización implica un 3\% de aumento en el ATI. Diversas fuentes (Zandbergen et al., 2000; May, 2001) señalan que por sobre 10 como tasa de impermeabilización, la cuenca pasa de un estado natural a uno impactado; por sobre 30, el medio está degradado, y por sobre 45 , es inhóspito para la vida silvestre. De acuerdo a los niveles de impacto causados por la urbanización, sólo la cuenca de Macul-San Ramón presentaría daños significativos, mientras que Arrayán-Las Gualtatas, Chicureo y Pirque se encontrarían aún en una situación de bajo impacto.

\subsection{Ecología de paisajes}

Entre 1989 y 2003 se ha experimentado una disminución general en el área total cubierta por parches vegetales en el piedemonte andino de Santiago (tabla 2): en la cuenca de Macul-San Ramón ésta ha alcanzado a 2.294 hectáreas, equivalentes a un 34\% de la superficie. Le sigue la cuenca de Arrayán-Las Gualtatas con una pérdida total de 1.789 hectáreas, es decir, un $28 \%$ de su superficie, y finalmente Chicureo con una reducción total de 752 hectáreas o un $17 \%$ de su superficie. La única cuenca que presenta el proceso inverso es Pirque, donde la superficie total de parches vegetales aumentó en 779 hectáreas, que equivale a un incremento del $3,4 \%$ en los últimos catorce años. 
En el caso de Macul-San Ramón (figura 9), los parches vegetales correspondientes a tierras agrícolas ubicados en el sector sur-este de la cuenca han disminuido significativamente como producto de la urbanización, transformando lo que fue un continuo vegetal en paisajes fragmentados y aislados. En las cuencas de Chicureo y Arrayán-Las Gualtatas la urbanización ha sido también el principal factor de fragmentación y reducción de los parches vegetales, que en el primer caso, correspondían a tierras agrícolas ubicadas en la parte baja de la cuenca; en un segundo caso, se trataba de bosques esclerófilos (adaptados a la sequedad y frío invernal) localizados en los bordes de los cauces. En el caso de Pirque, la conservación de las áreas agrícolas y la urbanización de muy baja densidad no han afectado mayormente a la ecología del paisaje.

Respecto a la evolución del número de parches vegetales, la Tabla 2 permite observar la ocurrencia de procesos diferentes. En el caso de Macul-San Ramón ha ocurrido atrición y fragmentación, ya que se ha reducido la superficie $(-34 \%)$ y aumentado el número de parches $(32,8 \%)$. En Pirque, por el contrario, la fragmentación ha sido menor (14\%) y ha aumentado la superficie (3,4\%). En Arrayán-Las Gualtatas y Chicureo, especialmente en la primera, ha tenido lugar una extinción, con la consiguiente reducción de ambos, la superficie y el número de parches. Sólo la cuenca de Pirque ha aumentado su superficie vegetada. La urbanización del piedemonte andino está contribuyendo significativamente a la desertificación de esta cuenca mediterránea, en circunstancias que lo que más se requeriría sería mantener o aumentar sus áreas verdes.

El análisis de la evolución del tamaño promedio de los parches en las cuatro cuencas indica que en todos los casos ha habido una reducción (tabla 1). En la cuenca de Macul-San Ramón el tamaño medio ha descendido de 3,31 a 1,64 hectáreas (50,4\%), lo que corresponde al caso más dramático. En el caso de Pirque, la reducción de la superficie ha sido de

Figura 9. Pérdida de parches vegetales en la Cuenca de Macul-San Ramón (1989-2003).

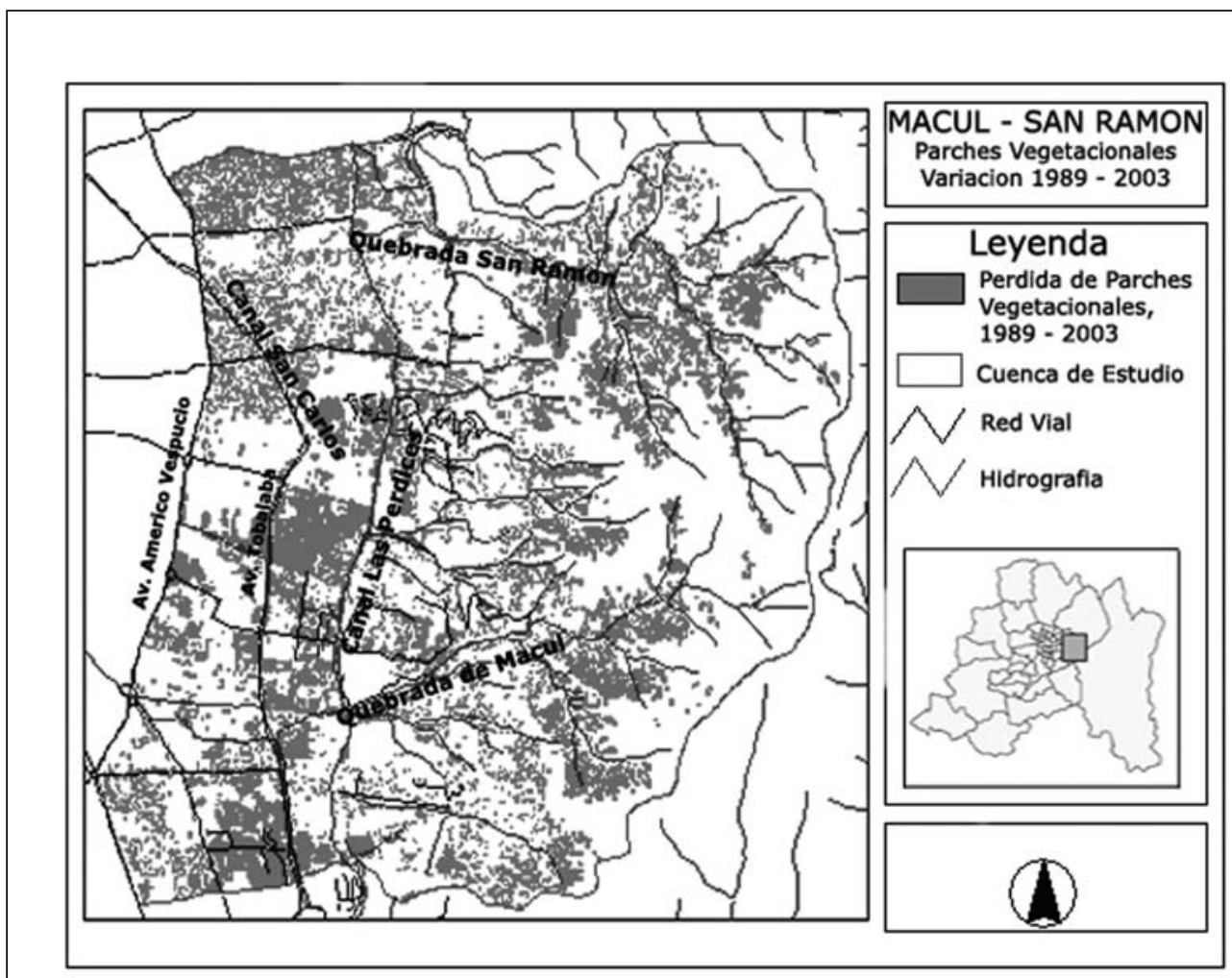


Tabla 2. Evolución de los atributos espaciales de la estructura del paisaje de cuatro cuencas del piedemonte andino de Santiago (1989-2003).

\begin{tabular}{|c|c|c|c|c|c|c|c|c|c|c|c|c|}
\hline & \multicolumn{2}{|c|}{ Área total } & \multicolumn{2}{|c|}{$\begin{array}{l}\mathrm{N}^{\circ} \mathrm{de} \\
\text { parches }\end{array}$} & \multicolumn{2}{|c|}{$\begin{array}{c}\text { Tamaño } \\
\text { promedio de } \\
\text { los parches }\end{array}$} & \multicolumn{2}{|c|}{ Perímetro total } & \multicolumn{2}{|c|}{$\begin{array}{l}\text { Perímetro } \\
\text { por parche }\end{array}$} & \multicolumn{2}{|c|}{$\begin{array}{c}\text { Perímetro total } \\
\text { /superficie } \\
\text { total de } \\
\text { la cuenca }\end{array}$} \\
\hline & Há. & $\%$ & No & $\%$ & Há. & $\%$ & $\mathrm{Km}$. & $\%$ & M. & $\%$ & Km/Há & $\%$ \\
\hline $\begin{array}{l}\text { Arrayán- } \\
\text { Las Gualtatas } \\
\end{array}$ & -1789 & $-28 \%$ & -1250 & $-24 \%$ & $-0,06$ & $-4,8 \%$ & -531 & $-24,3 \%$ & 4 & $0,09 \%$ & 17 & $6,5 \%$ \\
\hline \begin{tabular}{|l|} 
Macul- \\
San Ramón \\
\end{tabular} & -2294 & $-34 \%$ & 664 & $32,8 \%$ & $-1,67$ & $-50,4 \%$ & -7 & $-5 \%$ & -201 & $-28,6 \%$ & 93 & $45,2 \%$ \\
\hline Pirque & 779 & $3,4 \%$ & 428 & $14 \%$ & $-0,74$ & $-9,6 \%$ & 152 & $5,1 \%$ & -85 & $-8,2$ & 2 & $1,4 \%$ \\
\hline Chicureo & -752 & $-17 \%$ & -100 & $-5,7 \%$ & $-0,31$ & $-12,4 \%$ & -29 & $-3,1 \%$ & 15 & 2,7 & 38 & $17,6 \%$ \\
\hline
\end{tabular}

7,63 a 6,89 hectáreas (9,6\%). En la cuenca de Chicureo la variación del tamaño de los parches registra una caída desde 2,49 a 2,18 hectáreas (12,4\%) y en Arrayán-Las Gualtatas se han producido bajas desde 1,23 a 1,17 hectáreas (4,8\%).

Según estos antecedentes, la reducción más significativa del tamaño de los parches se registra en la cuenca de Macul-San Ramón, donde han llegado a ocupar la mitad de su superficie original en tan sólo 14 años. Si se considera que la calidad ambiental de una cuenca es proporcional al número y tamaño de sus parches vegetales (Romero et al., 2001), esta cuenca sería la que ha perdido mayores funciones y servicios ambientales.

Un caso crítico es el que presenta la cuenca de Arrayán-Las Gualtatas, en la que el tamaño final de los parches alcanza sólo a 1,17 hectárea, lo que limita severamente la supervivencia de especies más vulnerables o de amplio rango de hogar (que requieren mayores superficies continuas para su existencia). Esta cuenca también registra una pérdida de cantidad y calidad de sus servicios ambientales, en especial en la parte baja, sometida a los efectos de una urbanización acelerada que ha deforestado las laderas y fondos de valle. La dominancia de fragmentos vegetales pequeños y aislados sugiere un efecto de borde importante en favor de la matriz urbana. En general, en las cuatro cuencas el tamaño promedio de los parches se ha visto alterado por la disección y hundimiento del tamaño, perforación y atrición de espacios naturales, suburbanización e interrupción de corredores vegetales.

El perímetro promedio de los parches ha experimentado solo pequeñas variaciones, del orden del $5 \%$ (tabla 1) en el período analizado, lo que indicaría que la potencialidad de intercambio de materia y energía entre la matriz y las zonas interiores de los parches ha variado muy poco. Si se tratara de aumentar la influencia de los parches sobre la matriz urbana, desde luego que los tamaños y los perímetros deberían haber aumentado proporcionalmente.

En la cuenca de Arrayán-Las Gualtatas, sin embargo, el perímetro total ha disminuido en 531 kilómetros, es decir, en un $24 \%$, lo que significaría una disminución en la exposición de los ecosistemas a las perturbaciones provenientes de la matriz urbana, lo que podría tener efectos beneficiosos para los parches que ocupan la parte baja de la cuenca, donde se observan los más altos índices de urbanización y los mayores volúmenes de tráfico de personas y vehículos, que repercuten de manera negativa sobre las condiciones interiores de los parches. Sin embargo, esta disminución del perímetro total afecta directamente a las poblaciones de especies que viven y se desarrollan cercanas al perímetro de los parches, llamadas "especies de borde", siendo los depredadores, especialmente las aves, los más adaptados a estas condiciones debido a los patrones lineales de sus territorios de caza (Forman, 1997). Estas especies ven reducido de manera considerable su hábitat disponible. De igual manera, se reducen los servicios ambientales que los parches vegetales prestan a la ciudad, en la medida que la planificación ecológica debería asegurar que las áreas urbanas dispongan de un flujo permanente y poderoso de aire, agua, sedimentos y organismos vivos generados en las áreas naturales.

Respecto a las variaciones en el perímetro promedio de los parches vegetales en el período de estudio, se observa que Pirque presenta los mayores valores, 1.025 y 940 metros en los años 1989 y 2003, respectivamente. En las otras tres cuencas los parches 
presentan perímetros cercanos a 500 metros, con lo que su capacidad de albergar "especies de interior", que son las que necesitan superficies mínimas sin perturbaciones para desarrollarse adecuadamente, se reduce considerablemente (Sukkop, 1991). Otro tanto debería ocurrir con la cantidad y calidad de los servicios ambientales que ofertan a la salud de la ciudad. Los parches de formas y bordes complejos e irregulares, de mayor perímetro, tienen una mayor presencia en los sectores altos y están asociados a los procesos naturales (Burel y Baudry, 2002).

\subsection{Areas Sensitivas Ambientales}

Las Áreas Sensitivas Ambientales se ubican en las cuatro cuencas en torno al sistema de drenaje de la red hídrica, especialmente sobre sus partes altas, donde se mantienen espacios seminaturales y naturales. Las áreas ambientalmente críticas, por el contrario, se ubican principalmente en la parte baja de las cuencas, que es la más afectada por los procesos de urbanización. La única excepción lo constituye la cuenca de Arrayán-Las Gualtatas (figura 10), en que estas áreas corresponden a espacios seminaturales controlados por las pendientes. Las ASA de esta cuenca son escasas (ocupan el 7,4\% de su superficie) y coinciden con sectores que están siendo urbanizados, formados por remanentes de bosque nativo semidenso, lechos del río y algunas quebradas.

Pirque (figura 11) es la cuenca que presenta más áreas sensitivas ambientales (45,2\% de la superficie total), debido a la mantención de sus rasgos rurales. En los sectores de alta pendiente, estas áreas se asocian a la presencia de remanentes de bosques nativos de tipo esclerófilo, y en los sectores planos, al predominio de plantaciones agrícolas. Las áreas ambientalmente críticas de esta cuenca (10,3\% de la superficie) corresponden al lecho de inundación del río, el cual se encuentra desprovisto de vegetación, e incluyen además a zonas con bosque nativo semidenso de la parte alta de la cuenca.

En la cuenca Macul-San Ramón, las Áreas Sensitivas Ambientales cubren un 18,4\% de la superficie total y se encuentran localizadas adyacentes a los cauces de las quebradas de similares nombres y en áreas agrícolas remanentes, que actúan como zonas de amortiguación para los procesos provenientes del sector alto de la cuenca y de interfaz para los flujos entre la llanura y el piedemonte andino. Las áreas ambientalmente críticas de esta cuenca (que ocupan

Figura 10. Áreas Sensitivas Ambientales en la cuenca de Arrayán-Las Gualtatas (2003).

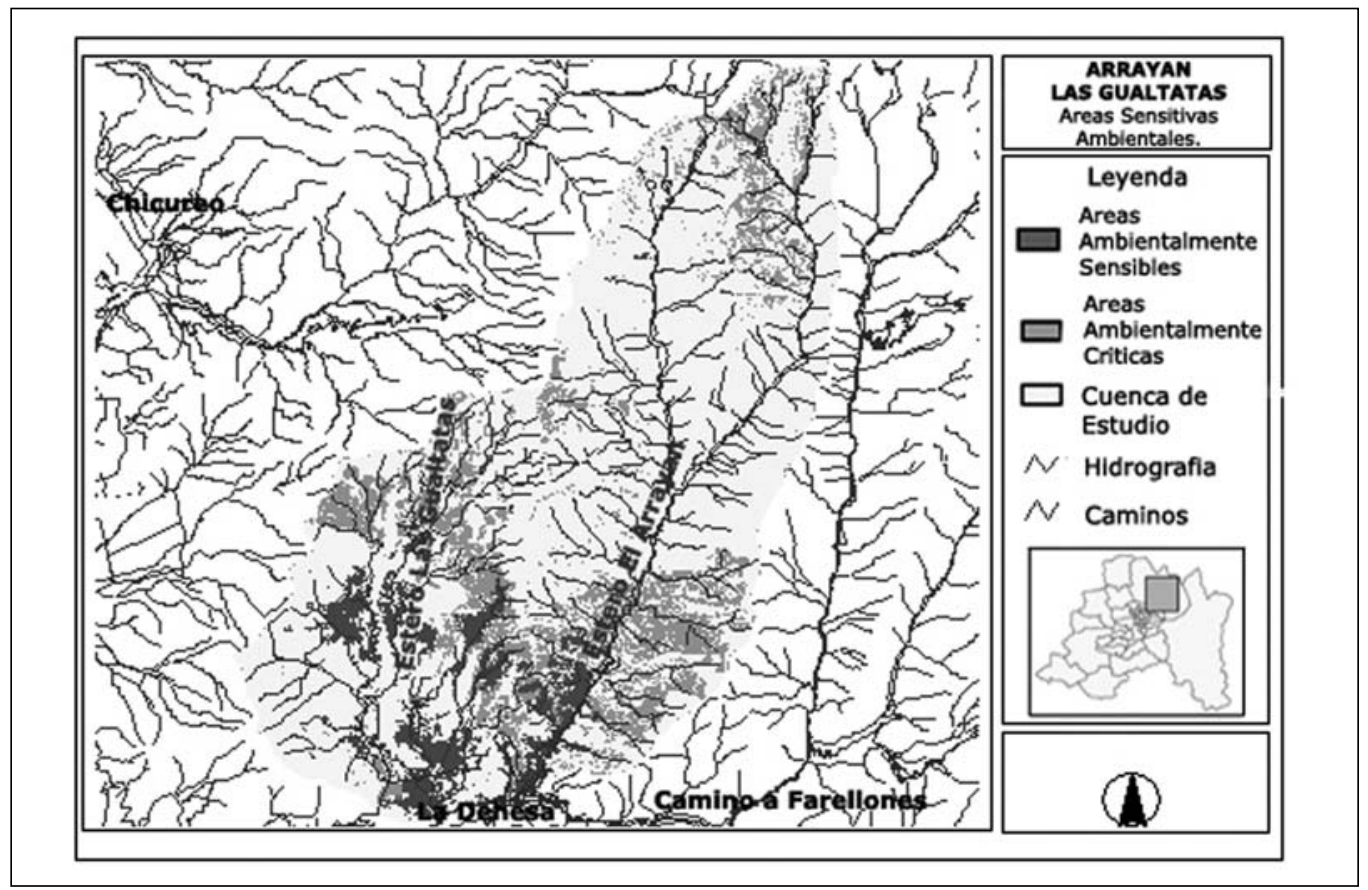


Figura 11. Áreas Sensitivas Ambientales en la cuenca de Pirque (2003).

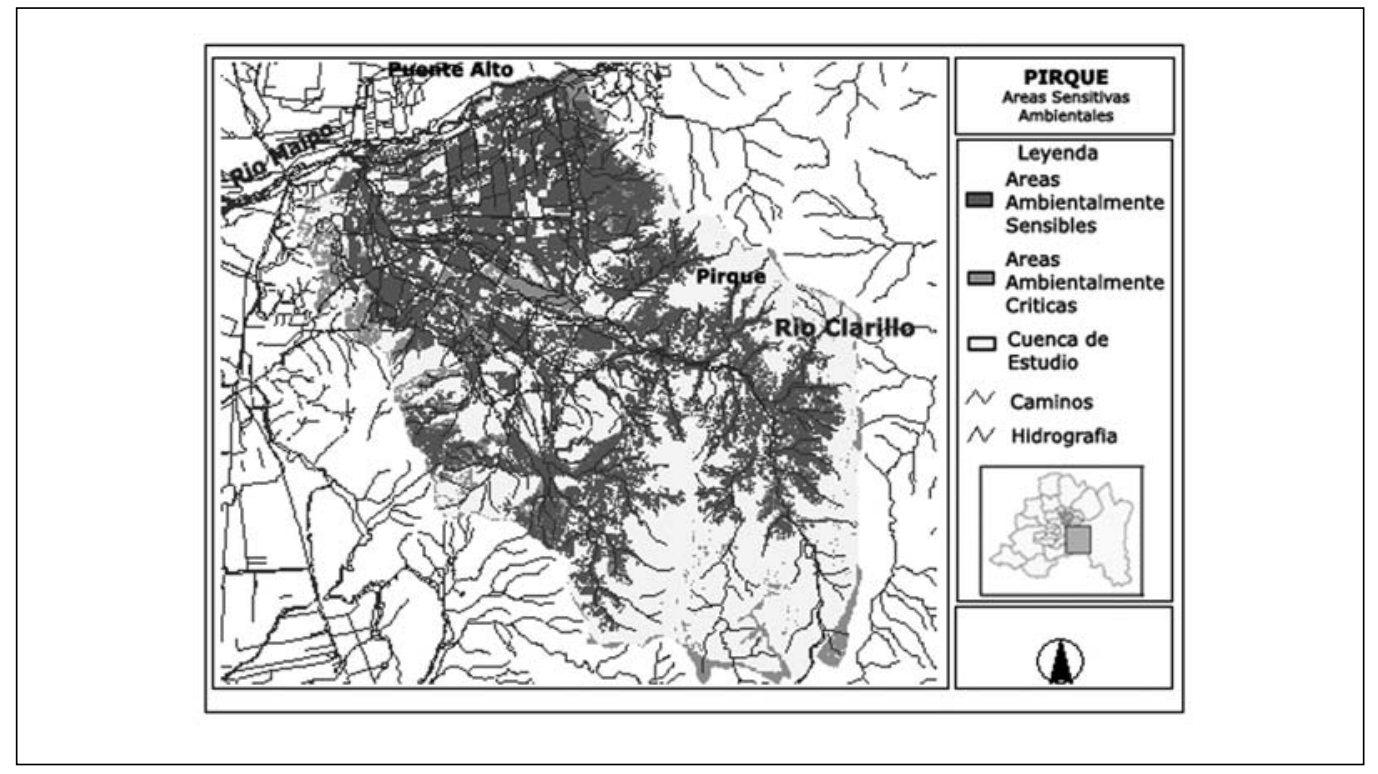

el 5,7\% de su superficie) corresponden a sectores urbanos consolidados y de alta densidad, donde las áreas verdes son muy escasas.

La cuenca de Chicureo, por su parte, tiene un 20,7\% de superficie cubierta por Áreas Sensitivas Ambientales, que corresponden a zonas agrícolas localizadas en la parte baja de la cuenca y a quebradas cubiertas con matorral arborescente semidenso en la parte alta. Las áreas ambientalmente críticas alcanzan a un $20,4 \%$ de su superficie y están asociadas a zonas agrícolas, praderas naturales y quebradas desprovistas de vegetación.

\section{Conclusiones}

La gestión territorial de la ciudad de Santiago se realiza sobre un Plan Regulador Metropolitano que no considera a la cuenca ambiental como marco de referencia explícito. A su vez, dicho instrumento territorial no ha podido controlar la expansión geográfica de la ciudad, por lo que se han propuesto Zonas de Desarrollo Urbano Condicionado, lo que significa nuevos riesgos para las cuencas del piedemonte andino, que es una de las zonas más vulnerables frente al crecimiento urbano en la actualidad. Sin embargo, por otro lado, la evaluación ambiental caso a caso abre oportunidades y genera exigencias que podrían resultar útiles para la introducción de la pla- nificación, evaluación y zonificación ecológica y ambiental de las áreas de expansión urbana.

La regulación de la expansión urbana hacia el piedemonte de Santiago sólo ha considerado restricciones altitudinales que son cada vez más difíciles de respetar, sin tener en cuenta que las cuencas y subcuencas son sistemas ambientales complejos y dinámicos que requieren considerar las características particulares de cada sector en relación con el conjunto, y disponer de criterios que permitan conocer anticipadamente no sólo la conveniencia y pertinencia de urbanizar, sino que además, cómo, cuándo y dónde hacerlo. Ello aumenta las posibilidades de negociación entre los organismos públicos y los agentes inmobiliarios y flexibiliza criterios que, por rígidos, no siempre resultan ser útiles. Lo que definitivamente no resulta conveniente es seguir urbanizando el piedemonte andino sin considerar sus dramáticos efectos sobre los riesgos naturales y la salud de la cuenca que acoge a la ciudad de Santiago. Ello ha sido una vez más refrendado en el invierno del año 2005, por las inundaciones de viviendas y centros comerciales y por la destrucción de importantes infraestructuras urbanas, tales como avenidas y calles, canales y ductos.

La urbanización de las cuencas del piedemonte de Santiago ha incidido en la degradación de las funciones y servicios ambientales de una ciudad se- 
veramente afectada por emergencias ambientales, tales como altas concentraciones de contaminantes atmosféricos e hídricos, aluviones e inundaciones. Algunos de esos atributos, como la productividad vegetal y las concentraciones de biomasa, disminuyen en la misma medida que aumenta la urbanización, tendencia que debe ser controlada y revertida. Esta disminución de la calidad ambiental es aun mayor en las áreas de urbanización reciente, aunque no se observa una correlación espacial directa entre ambas variables en general, y en particular respecto al balance hídrico de las cuencas. Ello se debería a la imposibilidad de desagregar o desacoplar a la urbanización de los procesos naturales hidrológicos, climáticos, geomorfológicos y biogeográficos que afectan a las cuencas, y que dependen especialmente del tipo y fases del desarrollo urbano, expresadas en porcentajes de las superficies totales urbanizadas y en la densidad y diseño de las urbanizaciones.

El impacto de la urbanización de las cuencas sobre la hidrología superficial depende más bien del área total impermeabilizada-que a su vez representa la compleja combinación del mosaico de los usos y coberturas del suelo, ponderados para la totalidad de las cuencas- que exclusivamente de la superficie urbanizada. Este hecho es relevante por cuanto distintas estrategias de densificación y utilización del espacio implican distintos efectos sobre el funcionamiento y salud ambiental de las cuencas. Un proceso de urbanización que propone la reforestación de las laderas y suelos desnudos, respeta la existencia de áreas de recarga natural de los acuíferos, protege las áreas cubiertas por vegetación nativa, excluye la ocupación de lechos de inundación y la interrupción de buffers riparianos y cauces fluviales, que asegura sus formas para que cumplan sus funciones de transporte de flujos y que contribuya a generar corredores y parches vegetales de mayor tamaño, podría llegar a ser perfectamente sustentable desde el punto de vista ambiental. Para ello se requiere el diseño e implementación de programas de gestión integrada de la totalidad del territorio ocupado por las cuencas del piedemonte de Santiago.

La consideración de estas interacciones espaciales y ambientales al interior de las cuencas advierte sobre la amenaza que significa intervenir la naturaleza a raíz de la instalación de proyectos residenciales, comerciales o de infraestructuras aisladas, lo que re- afirma la necesidad de contar con planes reguladores comunales e intercomunales. Respecto al control de las inundaciones, se ha observado el interés de cada proyecto inmobiliario que se instala en el piedemonte por evitar las inundaciones en su interior, desviando u obstruyendo cauces naturales, construyendo colectores de aguas lluvias y aumentando la capacidad de sus sumideros, sin que exista una preocupación equivalente por el destino final de las aguas una vez que continúan su desplazamiento hacia las partes bajas de las cuencas. Las calles y avenidas han asumido el rol de cauces fluviales, facilitando con su pavimento la aceleración de los flujos de escurrimiento de las aguas, y con ello, la potencia de los procesos erosivos, la capacidad de transporte de sedimentos de gran tamaño y consecuentemente, la peligrosidad de las inundaciones y aluviones.

Las diferencias existentes en el comportamiento ambiental de las cuencas no dependen sólo de la expansión de la ciudad, sino también del conjunto de los usos del suelo que se conservan en su interior, puesto que existen importantes compensaciones territoriales entre las superficies urbanizadas y los usos y coberturas no urbanos que ocupan el resto: áreas agrícolas, conservación de áreas naturales, aumento de la permeabilidad de los suelos, instalación de áreas de infiltración, respeto por el ancho de los cauces fluviales y protección de la vegetación que cubre sus bordes. En consecuencia, es necesario gestionar a las cuencas urbanas como sistemas territoriales integrados y espacialmente jerarquizados.

Las tasas de impermeabilización de los diversos usos del suelo del piedemonte de Santiago resultan ser en general más bajas si se comparan con los valores de referencia proporcionados por la literatura internacional, lo que podría interpretarse como una oportunidad para conservan su calidad ambiental, controlando explícitamente las superficies, densidades y diseños urbanos, además de proteger los usos y coberturas de las tierras que sean ambientalmente más amistosos. Sólo se exceptuarían, por sus altos valores, las tasas de las cubiertas de matorrales arborescentes abiertos y semidensos, lo que obligaría a implantar planes especiales de reforestación y restauración de estos paisajes.

Las cuencas presentan, en consecuencia, una sensibilidad diferente frente a los impactos de la urbani- 
zación, pudiendo concluir que éstos son mayores mientras más natural sea el estado actual de las cubiertas y usos del suelo. La conservación y restauración de las cubiertas vegetales es un factor de gran relevancia, ya que cumplen diversas funciones y servicios ambientales, a pesar de lo cual es uno de los componentes ambientales mayormente afectados por los procesos de urbanización, en especial a través de su reemplazo y fragmentación de los paisajes. Los parches vegetacionales existentes, considerados como corredores vegetales de protección en torno a la red hídrica de las cuencas, no son suficientes en número ni ancho, por lo que no ejercerían la función de protección integral del piedemonte. Esto es especialmente riesgoso en cuencas cuya morfología está asociada a fuertes pendientes como Arrayán-Las Gualtatas y Macul-San Ramón. Los cauces de esta última cuenca no se encuentran lo suficientemente provistos de vegetación -principalmente asociadas a estratos arbóreos y arbustivos-, siendo conocidas por su enorme capacidad de transporte de sedimentos y generación de aluviones en períodos de lluvias intensas.

Para el caso de Arrayán-Las Gualtatas, los parches asociados a esta cuenca han disminuido su número y tamaño a superficies menores a una hectárea, lo que implica una mayor vulnerabilidad a los efectos de la matriz urbana, sobre todo en la parte baja de la cuenca, y una disminución de las funciones ambientales. Se puede observar además que muchas áreas desprovistas de vegetación pueden ser calificadas como áreas ambientalmente críticas, donde la restauración de parches y corredores vegetales contribuiría notablemente a la protección de los cauces y las partes más bajas de las cuencas.

La integridad, conectividad espacial y conservación de los parches vegetales de gran tamaño, junto con aquellos que presentan una mayor complejidad de sus estructuras, conforman las áreas ambientalmente sensitivas del piedemonte andino de Santiago, cuya mantención es de vital importancia para mantener la buena salud de las cuencas y de los sistemas ambientales que funcionan en torno a ellas. Estos parches prestan importantes servicios ambientales como hábitat de especies, corredores de biodiversidad, zonas de infiltración, producción de humedad y filtración de contaminantes. La urbanización desaprensiva de estas áreas ambientalmente sensitivas sería la principal responsable de la pérdida de la calidad y salud ambiental de la cuenca de Santiago, algo que, de acuerdo a los resultados obtenidos, aún constituye una oportunidad que salvaguardar. Ello, sin considerar aún todo el potencial paisajístico, cultural y simbólico que le otorga el piedemonte cordillerano, a través de su carácter andino, una ventaja competitiva irrepetible y única a la capital de este país.

\section{Referencias bibliográficas}

Arnold, C. y J. Gibbons (1996). "Impervious surface coverage: The emergence of a key environmental indicator". Journal of the American Planning Association, 62, 2: 243-258.

Barnes, K., J. Morgan y M. Roberge (2001). Impervious surfaces and the quality of natural and built environments. Baltimore: Departament of Geography and Environmental Planning, Towson University.

Burel, F. y J. Baudry (2002). Ecología de paisaje. Conceptos, métodos y aplicaciones. Barcelona: Mundi-Prensa.

Bustamante R. y A. Grez (1995). “Consecuencias ecológicas de la fragmentación de los bosques nativos". Ambiente y Desarrollo, 11, 2: 58-63.

Dramstad, W., J. Olson y R. Forman (1996). Landscape ecology. Principles in landscape architecture and land-use planning. Cambridge: Island Press.

Eastman, J.R. (1999). IDRISI for Windows. Worcester, M.A.: Clark University.

ERDAS (1997). Field Guide. Atlanta: ERDAS.

Forman, R. (1997). Land mosaics: The ecology of landscapes and regions. Cambridge: Cambridge University Press.

Martínez, A. y J. Navarro (1995). Hidrología forestal. El ciclo hidrológico. Valladolid: Secretariado de Publicaciones, Universidad de Valladolid.

May, C. (1998). "The cumulative effects of urbanization on small streams in the Puget Sount Lowland ecoregion". Proceedings of the Puget Sound Research. http://www.wa.gov/ puget_sound/Publications/98_proceedings/ pdfs/1a_may.pdf.

(2001). "A potential new strategy for stormwater. Management in the Puget Sound Region". Proceedings of the Puget Sound Research. http://www.wa.gov/puget_sound/ 
Publications/01_proceedings/sessions/oral/ 7d_may.pdf

Oliver, J. (1973). Climate and man's environment: An introduction to applied climatology. New York: John Wiley \& Sons, Inc.

Romero H., X. Toledo, F. Órdenes y A. Vásquez (2001). "Ecología urbana y gestión sustentable de las ciudades intermedias chilenas". Ambiente y Desarrollo, 17, 4: 45-51.

Romero, H., A. Vásquez y F. Órdenes (2003). “Ordenamiento territorial y desarrollo sustentable a escala regional, ciudad de Santiago y ciudades intermedias en Chile". Figueroa, E. y J. Simonetti (eds.), Globalización y biodiversidad: oportunidades y desafios para la sociedad chilena. Santiago: Editorial Universitaria, 167-224.

Stanuikynas, T. y D. Van Abs (2000). Impervious surface methodology. A methodology for defining and assessing impervious surfaces in the Raritan River basin. New Jersey: New Jersey Water Supply Authority.

Sukkop, H. (1991). Nature in cities: Development of flora and fauna in urban areas. Madrid: Ediciones MOPT.

Vásquez, A. (2002). Ecología de paisaje: una aplicación al estudio de la vegetación urbana en la ciudad de Quillota. Memoria para optar al título de Geógrafo. Santiago: Universidad de Chile.

Van Bohemen, H.D. y W.H. Janssen Van de Laak (2003). "The influence of road infrastructure and traffic on soil, water and air quality". Environmental Management, 31, 1: 50-68.

Zandbergen, P., H. Schreier, S. Brown, K. Hall y R. Bestbier (2000). Urban watershed management version 2.0. Vancouver: Institute for Resources and Environment, University of British Columbia. 